\title{
A política monetária brasileira por meio do canal de empréstimos bancários: uma análise do comportamento do spread entre 2002 e 2014.
}

\author{
Leonardo de Castro ${ }^{1}$ \\ Felipe Santos Tostes ${ }^{2}$
}

\begin{abstract}
Resumo: Este trabalho está relacionado à literatura sobre a condução da política monetária e à análise do funcionamento do canal de empréstimos bancários em economias emergentes. Para tanto, o caso da economia brasileira foi escolhido pelo fato de o Brasil ser um país onde, segundo Oreiro et al. (2006), um elevado spread bancário desestimula a tomada de crédito pelos investidores, possibilitando um menor ritmo de crescimento econômico. Com isso, o objetivo deste estudo é analisar a trajetória do spread bancário entre os anos de 2002 e 2014 e identificar de que forma a política macroeconômica, adotada pela autoridade monetária no período em questão, influenciou o seu comportamento. Para alcançar o objetivo principal, identificou-se a variável macroeconômica mais relevante, do ponto de vista econométrico, para a explicação do comportamento do spread bancário nesse mesmo período. Pode-se observar que, ao longo do período em análise, a variável spread apresentou uma tendência descendente acompanhada de oscilações causadas por choques. Ele foi caracterizado por momentos de picos associados à instabilidade do cenário econômico, tais como os anos que marcaram o início do primeiro governo Lula e a crise financeira de 2007. Também entre as variáveis explicativas analisadas, percebeu-se que, com exceção da taxa de inflação e o compulsório, o índice de atividade industrial e a Selic se comportaram de acordo com o que preconiza a literatura a respeito do assunto.
\end{abstract}

Palavras-chave: Canais de transmissão da política monetária. Economia brasileira. Política monetária. Spread bancário.

\begin{abstract}
This paper is related to the literature on the conduct of monetary policy and the analysis of the functioning of the bank lending channel in emerging economies.According to Oreiro et al. (2006), the Brazilian economy was chosen because of a high bank spread, discouraging the taking of credit by investors, allowing a slower pace of economic growth. Thus, the objective of this study is to analyze the trajectory of the banking spread between the years 2002 and 2014 and to identify the way in which the conduct of the macroeconomic policy adopted by the monetary authority in the period in question influenced its behavior. To meet the main objective, we identified the most relevant macroeconomic variable, from the econometric point of view, for explaining the behavior of the banking spread in the same period. It can be observed that over the period under analysis, that the spread variable presented a downward trend accompanied by oscillations caused by shocks. It was characterized by moments of peaks associated with the instability of the economic scenario, such as the years that marked the beginning of the first Lula government and the financial crisis of 2007. Also among the explanatory variables analyzed, it was noticed that with the exception of the rate of inflation and the compulsory, the index of industrial activity and the Selic behaved according to what the literature advocates on the subject.
\end{abstract}

Keywords: Banking spread. Brazilian economy. Monetary policy. Monetary policy transmission channels.

\footnotetext{
${ }^{1}$ Graduado em Economia na Universidade Federal Fluminense (UFF). E-mail: leonardcasttro@gmail.com ${ }^{2}$ Doutor em Economia pela Universidade Federal Fluminense (UFF). Professor do Curso de Ciências Econômicas da UFF/Campos. E-mail: felipesantostes@hotmail.com
}

Página 77 Caderno de Ciências Sociais Aplicadas, Vitória da Conquista/BA, vol. 14, n 24, ano 14, p. 77-96, jul/dez 2017. 


\section{Introdução}

Segundo Prates e Cunha (2011), a crise financeira global iniciada em $2007^{3}$ foi um marco na mudança na estratégia de condução da política macroeconômica adotada pelos países de economias ditas emergentes. Até as crises internacionais ocorridas no final da década de 1990 e início do século XXI, verificava-se, como reação a essas, a adoção de políticas econômicas restritivas com o objetivo de garantir a permanência do capital internacional no mercado doméstico. Segundo esses autores:

Essas iniciativas tiveram como denominador comum, em sua maior parte, a ação anticíclica, contrariamente ao padrão de política econômica adotado nas situações pregressas de instabilidade cambial e financeira. Assim, outra dimensão inédita da crise atual (além de sua origem no centro do sistema) consiste na mudança de postura desses governos, que priorizaram a sustentação da atividade econômica (CEPAL4; BIS $^{5}$ apud PRATES e CUNHA, 2011, p.68).

Ribeiro (2010) destaca que a adoção de altas taxas de juros pela autoridade monetária brasileira até 2007 não se apresentava sustentável ao longo do tempo, uma vez que essa conduta desestimulava o consumo interno e criava obstáculos para a obtenção de superávits comerciais. Em função disso, entre 2008 e 2009, além da redução da taxa Selic, o Banco Central adotou uma série de outras medidas para estimular o consumo interno.

Fato semelhante pode ser verificado na gestão do governo federal seguinte. No início do governo Dilma, pode-se dizer que o regime de metas de inflação continuou sendo um dos pilares da política macroeconômica, porém foi possível observar mudanças expressivas na condução da política monetária. Inicialmente verificou-se a adoção de uma estratégia gradualista no combate à inflação. No primeiro semestre de 2011, o COPOM decidiu aumentar em 1,7 pontos percentuais a taxa de juros. Fato verificado em cinco reuniões consecutivas. Com isso, no segundo semestre de 2011, verificou-se uma desaceleração da inflação na economia brasileira. Foi então que o Banco Central iniciou a adoção de uma política de redução da taxa básica de juros ao longo desse período e no curso do ano seguinte. Contribuiu para esse fato o agravamento da crise do euro e também o menor ritmo de alta dos preços

\footnotetext{
${ }^{3}$ Prates (2011) classifica a crise financeira global em cinco etapas. A primeira, denominada crise das hipotecas de alto risco do mercado imobiliário americano ou subprime, iniciada em junho de 2007. Segundo essa autora, depois disso, a crise se propagou para outros segmentos do mercado financeiro.

${ }^{4}$ CEPAL. Panorama de lainserción internacional de América Latina y el Caribe 2009-2010: crisis originada en el centro y recuperación impulsada por las economías emergentes. Santiago de Chile, 2010.

${ }^{5}$ Bank FOR INTERNATIONAL SETTLEMENTS - BIS. Annual Report. Basle, 2010.
}

Página 78 Caderno de Ciências Sociais Aplicadas, Vitória da Conquista/BA, vol. 14, n 24, ano 14, p. 77-96, jul/dez 2017. 
das commodities no mercado internacional e da demanda interna. Porém, ao iniciar um movimento inverso, a autoridade monetária surpreendeu os agentes econômicos (CAGNIN et al., 2012).

Cagnin et al. (2012) evidencia também que, além dessa mudança no comportamento da autoridade monetária em face do comportamento da taxa básica de juros, uma série de outras medidas do ponto de vista da política monetária marcaram os dois primeiros anos do governo Dilma. Primeiro, destaca a alteração nas regras da caderneta de poupança, cujo objetivo foi evitar uma migração dos fundos de investimento para a poupança. Em segundo lugar, está a redução da alíquota do imposto sobre operações financeiras de 3\% para 2,5\%. E, por fim, uma atuação de maneira anticíclica, o incentivo aos bancos públicos para que revertessem o processo de contração do crédito. Nesse período, o Banco do Brasil e a Caixa Econômica provocaram a queda de suas taxas de juros para que os bancos privados se vissem obrigados a também adotar tal medida.

Com isso, a hipótese deste trabalho é a de que a condução da política monetária influenciou o comportamento do spread bancário no período de estudo. O objetivo deste estudo é, portanto, analisar a trajetória do spread bancário entre os anos de 2002 e 2014 e, com base no modelo sugerido por Oreiro et al. (2006), identificar a variável macroeconômica mais relevante, do ponto de vista estatístico, para a explicação do comportamento do spread bancário nesse período.

Neste estudo, foi utilizada a definição utilizada por Oreiro et al. (2006), segundo os quais de spread representa a diferença entre a taxa de juros cobrada aos tomadores de crédito e a taxa de juros paga aos depositantes pelos bancos.

A evidência empírica, usando Mínimos Quadrados Ordinários (MQO) para o período de janeiro de 2002 a dezembro de 2014, é o resultado das estimações, com base no modelo estrutural adotada por Oreiro et al. (2006), os quais consideram que o spread é influenciado positivamente e de maneira relevante pela produção industrial, pela volatilidade da taxa de juros e também pelo seu nível. É o que evidencia o texto a seguir:

Assim, o spread é influenciado positivamente por um impulso de um desvio padrão na volatilidade da taxa de juros e pela taxa de juros em nível, com efeito persistente em ambos os casos ao longo dos 12 meses. O efeito do produto industrial sobre o spread é positivo, ainda que menor do que no caso da volatilidade e nível da taxa de juros. No tocante à inflação, não se observou uma influência significativa sobre o spread (OREIRO et al., 2006, p. 21-22).

Página 79 Caderno de Ciências Sociais Aplicadas, Vitória da Conquista/BA, vol. 14, n 24, ano 14, p. 77-96, jul/dez 2017. 
Além desta introdução, este trabalho está estruturado em cinco partes. A parte seguinte aborda o papel do empréstimo bancário como canal de transmissão da política monetária e a relevância do spread bancário. A terceira parte versa sobre a metodologia e a coleta de dados. Na quarta parte, realizam-se os testes econométricos e discutem-se os resultados. Na última parte são feitas as considerações finais.

\section{Revisão de literatura}

\section{O empréstimo bancário como canal de transmissão da política monetária}

De Mendonça (2001) apresenta a forma pela qual a política monetária é transmitida pelo canal de empréstimos bancários da seguinte forma:

[...] uma política monetária de contração da demanda agregada leva à redução de reservas e depósitos bancários (RB e DB), o que culmina com a redução no volume de empréstimos concedido pelos bancos (EB). Assim, com menos recursos disponíveis no mercado, tende a haver redução no nível de investimento e, por conseguinte, redução no produto (DE MENDONÇA, 2001, p. 69).

A relevância macroeconômica do canal de empréstimos bancários ficou amplamente conhecida com os estudos evidenciados em Bernanke e Blinder ${ }^{6}$ apud Souza Sobrinho (2003). Trata-se de uma versão modificada da IS-LM. Segundo esse autor:

[...]. A principal diferença entre o modelo de Bernanke e Blinder e o modelo IS-LM tradicional é que ele define três mercados (monetário, de crédito e de bens), e não apenas os dois mercados (monetário e de bens) que usualmente são postulados. A consideração de mais um ativo na economia (crédito) implica que o mercado de bens passa a ser afetado por duas taxas de juros: a taxa de juros sobre títulos, como no modelo tradicional, e a taxa de juros sobre empréstimos. Agora, os choques monetários afetam a demanda agregada tanto direta como indiretamente (nesse último caso, através do impacto sobre o custo e sobre a oferta de crédito). Portanto, a existência do banklendingchannel torna a política monetária mais potente em relação ao caso em que apenas o canal da taxa de juros é operante (SOUZA SOBRINHO, 2003, p. 21).

Souza Sobrinho (2003) ainda destaca que a existência do canal de crédito, nesse caso, o bancário, tem como fundamentação teórica a presença de assimetrias de informação. Além dessa premissa, o autor considera outras três fundamentais para o entendimento do canal de crédito: o canal

${ }^{6}$ BERNANKE, Bem; BLINDER, Alan. Credit, Money and aggregate demand. American Economic Review, v. 78, n. 2 , p. 435-439, May, 1988.

Página 80 Caderno de Ciências Sociais Aplicadas, Vitória da Conquista/BA, vol. 14, nº 24, ano 14, p. 77-96, jul/dez 2017. 
de crédito é uma fonte adicional de propagação de choques macroeconômicos com efeitos assimétricos e heterogêneos sobre a economia real; a eficácia de uma política monetária será muito impactada pela existência do canal de crédito; e por fim, a relação direta entre canal de crédito, estrutura financeira e variações econômicas associadas a crises financeiras.

\title{
A relevância do spread bancário
}

Segundo Oreiro et al. (2006), um dos principais entraves para a expansão do crédito no Brasil são as elevadas taxas de juros praticadas pelos bancos no país. A consequência disso é o baixo nível de crédito, considerado um dos principais fatores para a economia nacional crescer aquém dos níveis esperados.

Segundo Klein ${ }^{7}$ apud Oreiro et al. (2006), o spread bancário reflete o grau de monopólio do banco. De acordo com sua abordagem:

\begin{abstract}
A atividade da firma bancária se desenvolve, via de regra, num ambiente de mercado que é caracterizado pela presença de concorrência monopolista ou imperfeita, tanto no mercado de crédito como no mercado de depósitos. Isto significa que o banco tem poder de monopólio na fixação da taxa de juros em pelo menos um dos mercados em que opera, normalmente o mercado de crédito, comportando-se como um formador de preços (price-setter). Este poder de monopólio explicaria a escala de operação e as estruturas ativa e passiva do banco, levando em conta que as decisões de um banco individual seriam capazes de afetar as taxas que remuneram os componentes do passivo, assim como aqueles integrantes do ativo bancário. Portanto, o spread bancário reflete fundamentalmente - nesta abordagem - o "grau de monopólio" do banco, ou seja, a sua capacidade de cobrar um preço maior do que o custo marginal de produção dos serviços por ele oferecidos (OREIRO et al., 2006, p. 611).
\end{abstract}

Dessa forma, o spread torna-se um importante indicador para a mensuração do poder dos bancos no tocante à fixação de suas taxas. Quanto maiores as taxas, maiores serão as restrições para a ampliação do nível de crescimento da atividade econômica.

\section{Metodologia e dados}

\section{Modelo Econométrico e V ariáveis}

A metodologia deste estudo é a análise empírica do comportamento do spread bancário no Brasil. O modelo adotado é a regressão múltipla utilizada por Oreiro et al. (2006), no qual estão os

\footnotetext{
${ }^{7}$ Klein, M. A. A theory of the banking firm.Journal of Money, Credit and Banking, v. 3, n. 2, p. 205-218,1971.
}

Página 81 Caderno de Ciências Sociais Aplicadas, Vitória da Conquista/BA, vol. 14, n 24, ano 14, p. 77-96, jul/dez 2017. 
determinantes macroeconômicos do spread bancário no Brasil. Serão coletados os dados entre os meses de janeiro de 2002 e dezembro de 2014 para o modelo econométrico. Esse modelo se compõe das variáveis:

$$
\text { Spread }=\beta_{0}+\beta_{1} \text { ind }+\beta_{2} \text { Infl }+\beta_{3} \text { Selic }+\beta_{4} \operatorname{Comp}+\lambda(1)
$$

Onde as variáveis representam as seguintes séries:

- Spread bancário (Spread) - representa o spread médio das operações de crédito com recursos livres para taxas de juros pré-fixadas, considerados o total geral (pessoas físicas e pessoas jurídicas). Fonte: Banco Central do Brasil;

- Índice de produção industrial (Ind) - É adotado como proxy para o nível de atividade econômica. Fonte: Instituto Brasileiro de Geografia e Estatística (IBGE);

- Taxa de inflação (Infl) - Variável que mede a variação mensal do Índice de preços ao Consumidor Amplo IPCA. Fonte: Instituto Brasileiro de Geografia e Estatística (IBGE);

- Taxa de Juros Selic (Selic) - Principal instrumento de política monetária na adoção do regime de metas de inflação. Fonte: Banco Central do Brasil;

- Taxa de reservas compulsórias sobre depósitos a vista (Comp) - Representa os valores percentuais definidos pela autoridade monetária. Fonte: Banco Central do Brasil.

Considerando que a concentração do mercado bancário no Brasil é um fator central na determinação do spread bancário, foi incluída a variável dummy (choques) como proxy da utilização do instrumento de política monetária (taxa de juros Selic), na tentativa de alterar a concorrência no setor. A utilização dessa variável pressupôs a ocorrência desse choque de política monetária no seguinte período: i) nos primeiros anos do governo Dilma (outubro de 2011 a dezembro de 2013). Assim, uma variável dummy é introduzida no modelo e assume valor "1" para o período de outubro de 2011 a dezembro de 2013, e o valor "0" para o caso contrário.

A escolha desse modelo se fundamenta na argumentação de Afanasieff ${ }^{8}$ et al. apud Oreiro et al. (2006), segundo a qual, para o caso brasileiro, as variáveis macroeconômicas são mais relevantes que as microeconômicas. Nesses termos os autores afirmam:

\footnotetext{
${ }^{8}$ Afanasieff, T. S.; Lhacer, P. M.; Nakane, M. I.The determinants of bank interest spread in Brazil. Money Affairs, v. XV, n. 2, p. 183-207, 2002.
}

Página 82 Caderno de Ciências Sociais Aplicadas, Vitória da Conquista/BA, vol. 14, n 24, ano 14, p. 77-96, jul/dez 2017. 
[...] ao investigar se os fatores macro e microeconômicos são relevantes para explicar o comportamento do spread no País, sugerem, a partir dos resultados obtidos, que variáveis macroeconômicas - como a taxa básica de juros e o crescimento do produto - são os fatores mais relevantes para explicar tal comportamento (OREIRO et al., 2006, p.610).

Utilizou-se o método de Mínimo Quadrado Ordinário (MQO), pois, quando são válidas as hipóteses amostrais de linearidade dos parâmetros, da ausência de colinearidade entre as variáveis independentes, valor esperado dos erros igual a zero, homocedasticidade, não correlação serial entre os erros e distribuição normal, os estimadores $\beta$ s são os melhores estimadores não viesados e independentes e identicamente distribuídos (Wooldridge ,2010). Ainda segundo Wooldridge (2010), as hipóteses de não correlação serial dos $\operatorname{erros}(\operatorname{Corr}(\mu t, \mu s \mid X)=0$, para todo $t \neq s)$ e de homocedasticidade $(\mathrm{E}[\mu \mathrm{t} \mid \mathrm{X} 1, \ldots, \mathrm{XK}]=0)$ são fundamentais para que os estimadores sejam úteis para a análise em questão.

\section{Coleta de dados}

$\mathrm{Na}$ etapa de coleta de dados, foram selecionadas as séries temporais com periodicidade mensal e expressos na forma de número índice. Foram coletadas 156 observações. O primeiro dado foi observado em janeiro de 2002 e o último em dezembro de 2014.

A série spread bancário (spread) foi coletada do sistema gerenciador de séries temporais do Banco Central pela tabela 3955 (spread médio das operações de crédito com recursos livres preferenciais para a taxa de juros pré-fixada - total geral) no período de janeiro de 2002 até dezembro de 2012. Uma vez que essa série foi descontinuada, de janeiro de 2013 a dezembro de 2014, foi utilizada a tabela 20786 do mesmo sistema (spread médio das operações de crédito com recursos livres). Para tratar dessa descontinuidade, utilizou-se a seguinte metodologia:

- Foram calculadas as diferenças entre as observações da série 20786 e as observações correspondentes da mesma série, porém sem tendência;

- As observações encontradas no item acima foram somadas aos seus desvios das observações correspondentes da série 20786 sem tendência, acrescidos da média da série 3955 sem tendência.

A série índice de produção industrial (Ind) foi coletada com base na tabela 3653 do Instituto Brasileiro de Geografia e Estatística (produção física industrial por seções e atividades industriais).

Página 83 Caderno de Ciências Sociais Aplicadas, Vitória da Conquista/BA, vol. 14, n 24, ano 14, p. 77-96, jul/dez 2017. 
A taxa de juros selic (Selic) foi coletada segundo os dados da tabela 4189 do Banco Central (taxa de juros - selic acumulada no mês anualizada).

As reservas compulsórias sobre depósitos a vista (Comp) foram extraídas diretamente do sítio oficial do Banco Central na internet (tabela recolhimentos compulsórios - alíquotas), localizada no subgrupo moeda e crédito e contido no grupo tabelas especiais.

Os dados de inflação foram coletados da tabela 433 do IBGE (Índice nacional de preços ao consumidor-amplo (IPCA) - Var. \% mensal)

\section{Evidencias empíricas}

Testes de raíz unitária

De acordo com Gujarati e Porter (2011), a verificação empírica de séries temporais parte do princípio de que essas sejam estacionárias. Segundo tais autores:

Em linhas gerais, processo estocástico será chamado de estacionário se sua média e variância forem constantes ao longo do tempo e o valor da sua covariância entre os dois períodos de tempo depender apenas da distância, do intervalo ou da defasagem entre os dois períodos e não o tempo real ao qual a covariância é computada. (Gujarati e Porter, 2011, p. 734).

Desse modo, uma série temporal pode ser classificada como não estacionária caso a sua média ou sua variância varie com o tempo ou até mesmo as duas. Para verificar essa informação, realiza-se o teste de raiz unitária.

Gujarati e Porter (2011) ainda afirmam que, dado um modelo em que a série temporal $Y_{t}$ é descrita por:

$$
Y_{t}=\rho Y_{t-1}+u_{t} \mathrm{e}-1 \leq \rho \leq 1, \text { se } \rho=1
$$

O resultado é o que se denomina raiz unitária, ou seja, uma situação de não estacionaridade. Se o valor absoluto de $\rho$ for menor que um então a série temporal $Y_{t}$ é considerada estacionária. Nesse contexto, o autor recomenda a realização desse teste, pois a estimação da equação pelo método dos mínimos quadrados ordinários conduziria a realização do teste t com estimadores viesados.

Ao realizar-se o teste informal de observação do gráfico, com base na figura 1, é possível afirmar que as séries selic, ind e spread apresentam não estacionaridade em nível. Quanto às séries infl e comp, o teste informal não é tão conclusivo.

Página 84 Caderno de Ciências Sociais Aplicadas, Vitória da Conquista/BA, vol. 14, n 24, ano 14, p. 77-96, jul/dez 2017. 


\section{Cadernos de Ciências SOCIAIS APLICADAS}

Figura 1: Variável em Nível x Variável em $1^{a}$ Diferença

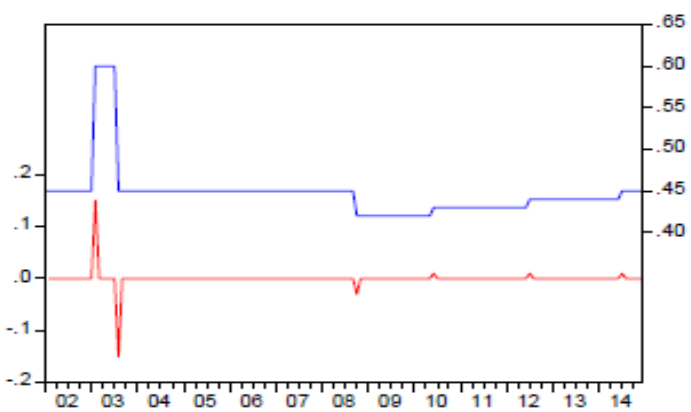

- COMP - DCOMP
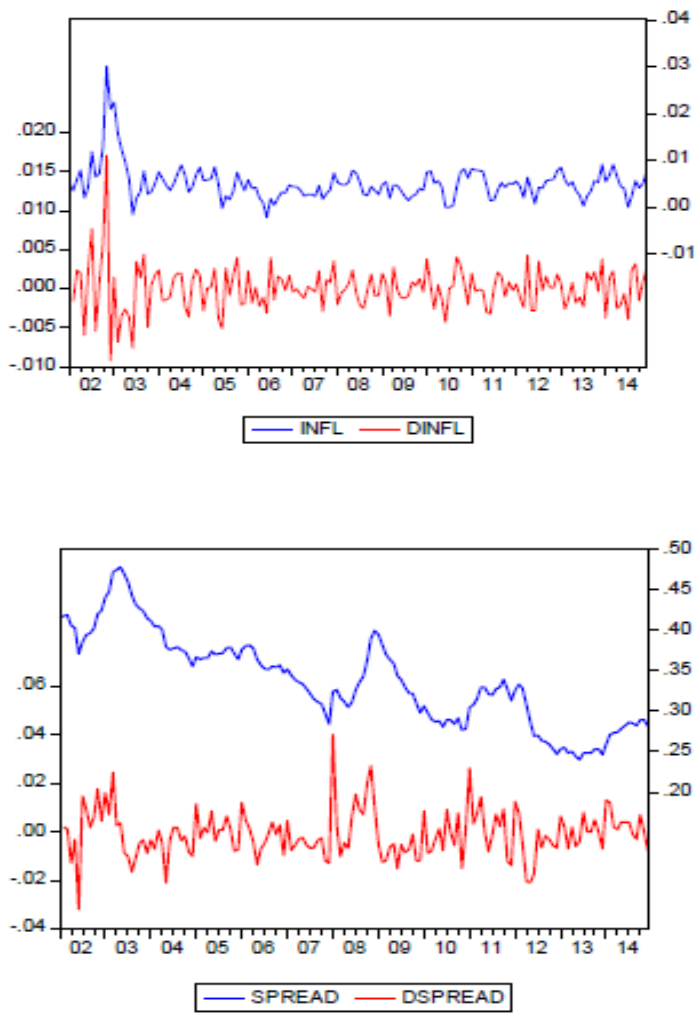

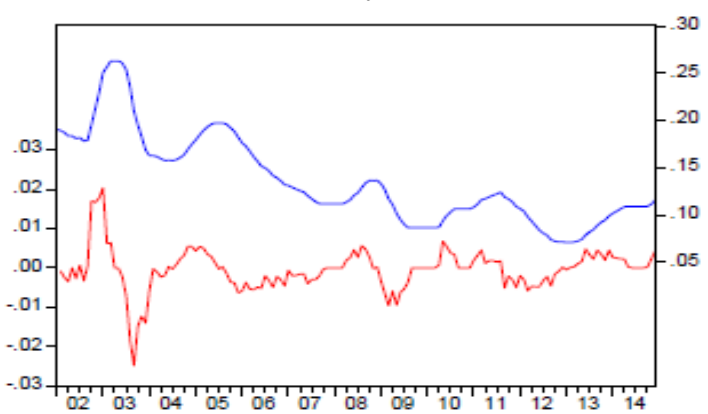

- SELIC —DSELIC

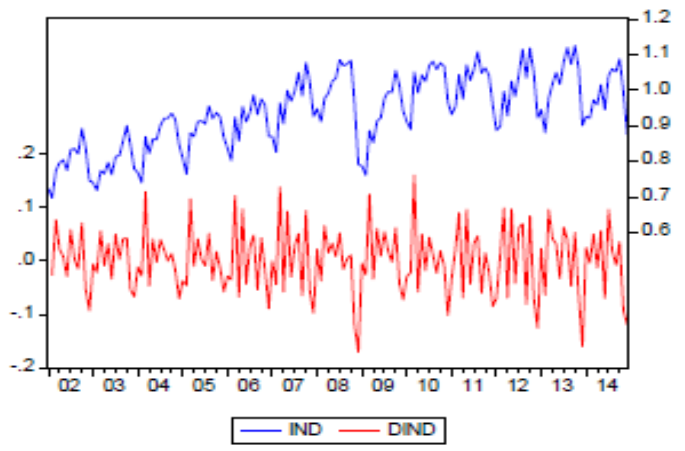

Para verificar resultados mais precisos quanto à estacionaridade ou não das séries, foi utilizado o teste de Dickey-Fuler aumentado (ADF). A tabela 1 apresenta os melhores resultados de acordo com o critério de Schwartz. De acordo com esse critério, as variáveis comp e infl apresentaram estacionaridade na segunda diferença e sem a inclusão da constante e da tendência. As variáveis ind e spread apresentaram estacionaridade na primeira diferença e, também, sem a inclusão da tendência e da constante. Já a Selic apresentou estacionaridade nível com a inclusão da tendência e da constante.

Página 85 Caderno de Ciências Sociais Aplicadas, Vitória da Conquista/BA, vol. 14, n 24, ano 14, p. 77-96, jul/dez 2017. 
Tabela 1: Testes Dickey-Fuler aumentado (Critério Schwartz)

\begin{tabular}{|c|c|c|c|c|c|c|c|c|}
\hline \multicolumn{9}{|c|}{ Resumo Teste ADF } \\
\hline VARIÁVEL & SCHWARTZ (SC) & LAG & TESTE & TIPO VARIAVEL & INCLUSAO & $1 \%$ & $5 \%$ & $10 \%$ \\
\hline comp & -6.000724 & 12 & -7.15 & $2 \mathrm{~d}$ & $\mathrm{c}$ & -2.58 & -1.94 & -1.62 \\
\hline ind & -3.630664 & 11 & -3.30 & $1 \mathrm{~d}$ & $\mathrm{c}$ & -2.58 & -1.94 & -1.62 \\
\hline infl & -9.041857 & 10 & -7.76 & $2 \mathrm{~d}$ & $\mathrm{c}$ & -2.58 & -1.94 & -1.62 \\
\hline selic & -8.817783 & 1 & -4.33 & 1 & $\mathrm{~b}$ & -4.02 & -3.44 & -3.14 \\
\hline spread & -6.459384 & 0 & -9.37 & $1 \mathrm{~d}$ & $\mathrm{c}$ & -2.58 & -1.94 & -1.62 \\
\hline
\end{tabular}

\section{Análise da cointegração}

Antes de se realizar os testes de cointegração, é preciso apresentar o conceito de regressão espúria. Esse fenômeno ocorre quando a regressão de uma variável de série temporal em relação a outras, também do tipo série temporal, apresenta resultados sem sentido. Uma maneira de verificar se o modelo estimado é espúrio é mediante o teste de cointegração (GUJARATI e PORTER 2011).

O teste de cointegração, ainda segundo esses autores, indica que, mesmo quando as séries temporais se apresentem individualmente como não estacionárias, uma combinação linear dessas pode se apresentar de forma estacionária. Assim, duas ou mais variáveis são cointegradas, quando existir uma relação de longo prazo, entre elas, ou seja, uma relação de equilíbrio. Dessa forma, a realização desse teste se apresenta tal qual uma ferramenta de suma importância para evitar casos em que a regressão pode ser classificada como espúria.

Isso exposto e diante dos resultados apresentados, pode-se dizer que as variáveis cointegram.

\section{Método dos mínimos quadrados ordinários}

Segundo Gujarati e Porter (2011), o tratamento de dados de séries temporais deve supor que as mesmas sejam estacionárias. Porém, segundo Sims ${ }^{9}$ apud Oreiro et al. (2006) a recomendação é para que o modelo seja estimado com as variáveis em nível, pois o objetivo principal é identificar a relação entre as variáveis e não os parâmetros estimados.

Tudo isso é corroborado ao se comparar o resultado do modelo da regressão cujas variáveis estão em nível com aquele nas quais essas estavam expressas pelas suas primeiras diferenças. Dessa

${ }^{9}$ SIMS, C. (1980) "Macroeconomics and reality". Econometrica, v. 48, n. 1, p. 1-48.

Página 86 Caderno de Ciências Sociais Aplicadas, Vitória da Conquista/BA, vol. 14, n 24, ano 14, p. 77-96, jul/dez 2017. 


\section{- Cadernos de Ciénclas SOCIAIS APLICADAS}

forma, percebeu-se que, estatisticamente, a qualidade do ajustamento do modelo no primeiro caso foi superior.

Ao analisar o coeficiente de determinação $\mathrm{R}^{2}$, percebe-se que, na regressão em nível, esse coeficiente é capaz de explicar aproximadamente $85 \%$ da variação na variável dependente. Nesse modelo, os p-valores obtiveram um resultado inferior a 0,05 , o que torna possível rejeitar a hipótese nula de que as variáveis explicativas são estatisticamente iguais a zero.

O comportamento dos estimadores indica que uma redução de 1 ponto percentual na variável ind provoca um aumento de 0,13 pontos percentuais na variável spread, mantendo as demais variáveis explicativas constantes. No caso da variável comp, uma redução desta em 1 ponto percentual, mantendo as demais variáveis explicativas constantes, é capaz de promover um amento na variável spread de 0,19 pontos percentuais para que spread. Já a variável Selic apresenta uma relação direta, ou seja, sua variação em 1 ponto percentual é capaz de promover uma variação de aproximadamente 1,02 pontos percentuais na variável spread.

A estatística Durbin Watson apresenta um valor relativamente pequeno. O que pode indicar sinais de autocorrelação. Porém esse teste será realizado mais a frente.

Os resultados da regressão estão apresentados na tabela 2.

Tabela 2: Resultado da regressão com variáveis em nível

\begin{tabular}{|c|c|c|c|c|}
\hline \multicolumn{5}{|c|}{$\begin{array}{l}\text { DependentVariable: SPREAD } \\
\text { Method: LeastSquares } \\
\text { Sample: 2002M01 2014M12 } \\
\text { Includedobservations: } 156\end{array}$} \\
\hline Variable & Coefficient & Std. Error & t-Statistic & Prob. \\
\hline $\mathrm{C}$ & 0.421955 & 0.037909 & 11.13059 & 0.0000 \\
\hline IND & -0.132785 & 0.024524 & -5.414454 & 0.0000 \\
\hline INFL & -1.562804 & 0.486070 & -3.215181 & 0.0016 \\
\hline SELIC & 1.019606 & 0.064839 & 15.72528 & 0.0000 \\
\hline COMP & -0.199895 & 0.072515 & -2.756584 & 0.0066 \\
\hline R-squared & 0.857347 & \multicolumn{2}{|c|}{ Meandependent var } & 0.338377 \\
\hline Adjusted R-squared & 0.853569 & \multicolumn{2}{|c|}{ S.D. dependent var } & 0.057092 \\
\hline S.E. ofregression & 0.021847 & \multicolumn{2}{|c|}{ Akaikeinfocriterion } & -4.777989 \\
\hline Sum squaredresid & 0.072070 & \multicolumn{2}{|c|}{ Schwarz criterion } & -4.680237 \\
\hline Log likelihood & 377.6831 & \multicolumn{2}{|c|}{ Hannan-Quinn criter. } & -4.738286 \\
\hline F-statistic & 226.8790 & \multicolumn{2}{|c|}{ Durbin-Watson stat } & 0.364822 \\
\hline Prob(F-statistic) & 0.000000 & & & \\
\hline
\end{tabular}

Fonte: Elaboração própria a partir da saída dos Eviews 9.0 
Ao analisar o coeficiente de determinação $\mathrm{R}^{2}$, percebe-se que na regressão em nível, esse coeficiente é capaz de explicar aproximadamente $88 \%$ da variação na variável dependente. Nesse modelo, os p-valores obtiveram um resultado inferior a 0,05. Dessa forma, é possível rejeitar a hipótese nula de que as variáveis explicativas são estatisticamente iguais a zero.

O comportamento dos estimadores indica que uma redução de 1 ponto percentual na variável ind provoca um aumento de 0,13 pontos percentuais na variável spread, mantendo as demais variáveis explicativas constantes. No caso da variável comp, uma redução desta em 1 ponto percentual, mantendo as demais variáveis explicativas constantes, é capaz de promover um amento na variável spread de 0,15 pontos percentuais para que spread. Já a variável Selic apresenta uma relação direta, ou seja, sua variação em 1 ponto percentual é capaz de promover uma variação de aproximadamente 0,94 pontos percentuais na variável spread.

Os resultados da regressão estão apresentados na tabela 3.

Tabela 3: Resultado da regressão com variáveis dummy (choques)

\begin{tabular}{|c|c|c|c|c|}
\hline \multicolumn{5}{|c|}{$\begin{array}{l}\text { DependentVariable: SPREAD } \\
\text { Method: LeastSquares } \\
\text { Sample: 2002M01 2014M12 } \\
\text { Includedobservations: } 156\end{array}$} \\
\hline Variable & Coefficient & Std. Error & t-Statistic & Prob. \\
\hline C & 0.413229 & 0.037351 & 11.06348 & 0.0000 \\
\hline IND & -0.134049 & 0.024071 & -5.569016 & 0.0000 \\
\hline INFL & -1.393744 & 0.481362 & -2.895417 & 0.0044 \\
\hline SELIC & 0.936289 & 0.071188 & 13.15226 & 0.0000 \\
\hline COMP & -0.148945 & 0.073790 & -2.018513 & 0.0453 \\
\hline DUMMY & -0.014059 & 0.005388 & -2.609422 & 0.0100 \\
\hline R-squared & 0.863542 & \multirow{7}{*}{\multicolumn{2}{|c|}{$\begin{array}{l}\text { Meandependent var } \\
\text { S.D. dependent var } \\
\text { Akaikeinfocriterion } \\
\text { Schwarz criterion } \\
\text { Hannan-Quinn criter. } \\
\text { Durbin-Watson stat }\end{array}$}} & 0.338377 \\
\hline Adjusted R-squared & 0.858993 & & & 0.057092 \\
\hline S.E. ofregression & 0.021438 & & & -4.809562 \\
\hline Sum squaredresid & 0.068941 & & & -4.692260 \\
\hline Log likelihood & 381.1458 & & & -4.761919 \\
\hline F-statistic & 189.8476 & & & 0.375810 \\
\hline Prob(F-statistic) & 0.000000 & & & \\
\hline
\end{tabular}

Fonte: Elaboração própria a partir da saída dos Eviews 9.0

Já a regressão com as variáveis explicativas expressas por meio da sua primeira diferença apresenta um coeficiente de determinação $\mathrm{R}^{2}$ de $18 \%$, ou seja, o modelo só é capaz de explicar 18\% do comportamento da variável spread. Já os p-valores da regressão com as variáveis explicativas se comportaram de tal modo que, com exceção da variável explicativa dselic, não foi possível rejeitar a

Página 88 Caderno de Ciências Sociais Aplicadas, Vitória da Conquista/BA, vol. 14, n 24, ano 14, p. 77-96, jul/dez 2017. 
hipótese nula para as demais, ou seja, as demais não são estatisticamente significantes. Esses resultados estão expressos na tabela 4.

Tabela4: Resultado da regressão com variáveis em $1^{a}$ diferença

\begin{tabular}{|c|c|c|c|c|}
\hline \multicolumn{5}{|c|}{$\begin{array}{l}\text { DependentVariable: DSPREAD } \\
\text { Method: LeastSquares } \\
\text { Sample (adjusted): 2002M02 2014M12 } \\
\text { Includedobservations: } 155 \text { afteradjustments }\end{array}$} \\
\hline Variable & Coefficient & Std. Error & t-Statistic & Prob. \\
\hline C & -0.002289 & 0.001365 & -1.676863 & 0.0957 \\
\hline INFL & 0.329733 & 0.216281 & 1.524557 & 0.1295 \\
\hline DSELIC & 0.625210 & 0.156630 & 3.991625 & 0.0001 \\
\hline DIND & 0.009567 & 0.011944 & 0.800992 & 0.4244 \\
\hline DCOMP & 0.001762 & 0.042978 & 0.040992 & 0.9674 \\
\hline R-squared & 0.182393 & \multicolumn{2}{|c|}{ Meandependent var } & -0.000870 \\
\hline Adjusted R-squared & 0.160590 & \multicolumn{2}{|c|}{ S.D. dependent var } & 0.009739 \\
\hline S.E. ofregression & 0.008923 & \multicolumn{2}{|c|}{ Akaikeinfocriterion } & -6.568677 \\
\hline Sum squaredresid & 0.011943 & \multicolumn{2}{|c|}{ Schwarz criterion } & -6.470502 \\
\hline Log likelihood & 514.0725 & \multicolumn{2}{|c|}{ Hannan-Quinn criter. } & -6.528800 \\
\hline F-statistic & 8.365543 & \multicolumn{2}{|c|}{ Durbin-Watson stat } & 1.678906 \\
\hline Prob(F-statistic) & 0.000004 & & & \\
\hline
\end{tabular}

Fonte: Elaboração própria a partir da saída dos Eviews 9.0

\section{Análise da heterocedasticidade}

A hipótese da homocedasticidade, de acordo com Gujarati e Porter (2011), é de suma importância para a aceitação do modelo clássico de regressão linear. Segundo essa hipótese, os termos de erro da regressão possuem a mesma variância, ou seja, as variâncias do termo de erro são constantes. Para aqueles casos em que essa condição não é satisfeita, tem-se a presença da heterocedasticidade.

Nessa abordagem, a hipóstese da homocedasticidade pode ser demonstrada da seguinte maneira:

$$
E\left(u_{i}^{2}\right)=\sigma^{2} \text { onde } i=1,2, \ldots, n e u=\text { termo de erro }
$$

Existem várias razões para que as variâncias dos termos deixem de ser constantes, tais como o viés de especificação do modelo, a presença de dados discrepantes e a transformação incorreta dos dados. Porém, ainda segundo esses autores, em um modelo de mínimos quadrados ordinários em que se verifica a presença da heterocedasticidade, os estimadores continuam sendo não tendenciosos, porém deixam de ser os melhores, ou seja, não possuem a variância mínima.

Página 89 Caderno de Ciências Sociais Aplicadas, Vitória da Conquista/BA, vol. 14, n 24, ano 14, p. 77-96, jul/dez 2017. 
Gujarati e Porter (2011) afirmam ainda que a detecção da presença da heterocedasticidade pode ser feita tanto por métodos informais, como a observação gráfica da estimação dos resíduos ao quadrado em relação a variável dependente, quanto por métodos formais, ou seja, testes como o de Breusch-Pagan-Godfrey. Nesse estudo, optou-se pela realização deste último.

O teste de Breusch-Pagan-Godfrey segue a distribuição qui-quadrado em que, caso o valor observado esteja fora da região crítica, ao nível escolhido de significância, é possível rejeitar a hipótese da homocedasticidade (GUJARATI e PORTER 2011).

Dessa forma, de acordo com o resultado deste teste realizado no Eviews 6.0, a função de distribuição de probabilidade para 4 graus de liberdade apresentou um resultado insignificante estatisticamente tanto ao nível 1\%, quanto a 5\%. Dessa forma, não é possível rejeitar a hipótese da homocedasticidade.

\section{Análise da autocorrelação}

O modelo clássico de regressão linear em Gujarati e Porter (2011) pressupõe também que o erro associado a uma observação não é influenciado pelo erro de outra. Quando esse pressuposto é quebrado tem-se a denominada presença de autocorrelação.

De acordo com os autores citados anteriormente, entre os motivos para a ocorrência da autocorrelação pode-se destacar: o viés de especificação do modelo; as defasagens e a inercia das séries temporais. Além disso, afirmam que, assim como na presença da heterocedasticidade, na presença de autocorrelação, os estimadores continuam sendo não tendenciosos, porém deixam de ser os melhores, ou seja, não possuem a variância mínima. Por fim, a detecção da autocorrelação pode ser feita mediante diversos testes, tais como o método gráfico, o teste das carreiras, o teste $d$ de Durbin-Watson e o teste de Breusch-Godfrey.

Dessa forma, o modelo de regressão, estudado aqui, apresenta a quebra do pressuposto da ausência de correlação.

\section{Discussão dos Resultados}

Ao analisar o modelo econométrico, é preciso fazê-lo sob a luz da teoria econômica. Dessa forma, primeiramente, é preciso identificar como ocorre a relação entre cada determinante macroeconômico e a variável dependente.

Página 90 Caderno de Ciências Sociais Aplicadas, Vitória da Conquista/BA, vol. 14, n 24, ano 14, p. 77-96, jul/dez 2017. 
Afonso, Kohler e Freitas (2009) afirmam que economias em crescimento criam um ambiente em que a probabilidade de inadimplência é menor e a possibilidade de atração de capitais se amplia. Desse modo, ocorre uma ampliação da oferta de crédito e esses ganhos de escala são acompanhados por uma redução dos custos de empréstimos. Sendo assim, a ampliação da atividade econômica possui uma relação inversa com o spread.

Conforme esses autores, a taxa básica de juros possui uma relação direta com o spread, principalmente porque a primeira reflete o estado de risco da economia. Soma-se a isso o seguinte fato: quanto maior a taxa de juros, maiores serão as rentabilidades para viabilizar um projeto.

Os autores afirmam também que o nível de risco, geralmente mensurado pela volatilidade de uma variável macroeconômica, como no caso da taxa de juros, ocasiona a aplicação de taxas de spreads mais elevadas.

Da Silva, Oreiro e de Paula (2007) ressaltam que uma elevação da taxa de inflação está associada com um aumento nos níveis de spread.

Quanto à taxa de juros, revelam:

[...] elevações nas taxas de juros básicas podem ocasionar uma maior variabilidade no nível da produção real e na lucratividade das firmas, elevando o risco de crédito, o que pode resultar em taxas de empréstimos e spreads maiores. (DA SILVA, OREIRO e DE PAULA, 2007, p. 216).

Já para a relação entre atividade econômica e spread, Da Silva, Oreiro e De Paula (2007) estão em consonância com a proposição de Afonso, Kohler e Freitas (2009), pois afirmam que um maior crescimento do produto ocasiona a diminuição da inadimplência bancária e do risco de crédito, o que acarreta a redução do spread.

Mesmo não sendo possível incluir no modelo a variável Volatilidade da taxa de juros, dadas as dificuldades citadas anteriormente, é importante apresentar o comportamento esperado para essa variável em relação ao spread. A volatilidade da taxa de juros, segundo Da Silva, Oreiro e De Paula (2007), é diretamente proporcional à instabilidade econômica. Dessa forma, maiores volatilidades na taxa de juros geram um impacto positivo e estatisticamente significante sobre o spread bancário.

Oreiro et al. (2006) apresentam as seguintes relações entre as variáveis explicativas e o spread: o spread é influenciado positivamente pela volatilidade da taxa de juros, pela taxa de juros em nível e também pela atividade industrial.

Página 91 Caderno de Ciências Sociais Aplicadas, Vitória da Conquista/BA, vol. 14, nº 24, ano 14, p. 77-96, jul/dez 2017. 
A tabela 4 a seguir demonstra as relações matemáticas entre as variáveis explicativas e a variável dependente apresentada anteriormente:

Tabela 4: Relação entre o spread e as variáveis explicativas

\begin{tabular}{|c|c|c|c|c|c|}
\hline Estudo & Ind & Infl & Comp & Selic & Vol \\
\hline Afonso, Kohler e Freitas (2009) & - & & & & + \\
\hline Da Silva, Oreiro e De Paula (2007) & - & + & + \\
\hline Oreiro (2006) & + & & & + & + \\
\hline
\end{tabular}

Fonte: Elaboração própria a partir da saída dos Eviews 6.0

Isso exposto, o modelo econométrico aplicado por meio do método dos mínimos quadrados ordinários e com as variáveis em nível apresentou os resultados de acordo com a seguinte regressão:

Spread $=0,42-0,13$ ind $+1,02$ Selic $-1,56$ Infl $-0,20$ Comp $+\lambda$

O índice de atividade industrial, utilizado como proxy da atividade econômica, comportou-se de acordo com as proposições de Kohler e Freitas (2009) e de Da Silva, Oreiro e De Paula (2007), exercendo uma influência negativa no spread bancário.

A taxa de juros Selic apresentou uma influência positiva no comportamento do spread bancário. Esse resultado ficou em consonância com aqueles apresentados no início desta seção.

O compulsório apresentou uma relação negativa em relação ao spread. Além disso, contrariando os resultados de estudos anteriores, seu estimador apresentou significância estatística.

Já a taxa de inflação se comportou de maneira diferente àquela esperada. Segundo o modelo de regressão, essa variável explicativa exerce uma influência negativa no comportamento do spread. Tal resultado não é confirmado pela teoria apresentada inicialmente e pode ser justificado pela ausência da variável volatilidade da taxa de juros modelo.

A volatilidade da taxa de juros foi considerada pelos estudos de Oreiro et al. (2006) a variável mais relevante para a explicação do spread bancário. A ausência de uma variável relevante pode ocasionar o problema denominado viés de especificação do modelo. Desse modo, Gujarati e Porter (2011) afirmam que o viés de especificação pode fazer com que o modelo econométrico não seja um bom reflexo da realidade.

Dessa forma, a relação negativa da inflação com spread, somada a significância estatística tanto desta variável quanto das reservas compulsórias, é um grande indício de que a ausência da variável volatilidade da taxa de juros ocasionou problemas associados ao viés de especificação do modelo.

Página 92 Caderno de Ciências Sociais Aplicadas, Vitória da Conquista/BA, vol. 14, n 24, ano 14, p. 77-96, jul/dez 2017. 


\section{Conclusão}

Conforme a literatura a respeito do tema em questão, as variáveis macroeconômicas são importantes para compreender o comportamento do spread no Brasil. Entre esses, os principais destaques são a volatilidade da taxa de juros e o nível da taxa de juros. Os resultados demonstraram que, do ponto de vista estatístico, todas as variáveis explicativas foram relevantes para a determinação do comportamento do spread bancário. Porém, era esperado que a variável inflação e a compulsório não apresentassem significância estatística.

Ao analisar os resultados da equação com base no método dos mínimos quadrados ordinários, destaca-se que a inflação não possui um comportamento compatível com o que é esperado pela teoria econômica, pois esta diz que há uma relação direta entre a inflação e o spread e os resultados apresentaram uma relação inversa.

Uma das hipóteses para a ocorrência desse problema é o viés de especificação, uma vez que a variável que mais determina o comportamento do spread, segundo a literatura sobre o assunto, não foi incluída no modelo.

Este estudo indica que, ao longo do período em análise, a variável spread apresentou uma tendência descendente acompanhada de um comportamento cíclico. Estes foram caracterizados por momentos de picos associados à instabilidade do cenário econômico, tais como os anos que marcaram o início do primeiro governo Lula e a crise financeira de 2007. Isso revela que a redução dos níveis de spread bancário no Brasil estará associada à estabilidade econômica.

\section{Referências}

AFONSO, José Roberto; KÖHLER, Marcos Antônio; FREITAS, Paulo Springer de. Evolução e determinantes do Spread bancário no Brasil. Texto para discussão, n ${ }^{\circ}$ 61. Centro de Estudos da Consultoria do Senado Federal. Brasília, agosto de 2009. Disponível em: http://www2.senado.leg.br/bdsf/bitstream/handle/id/162312/61.pdf Acesso em 21/09/2015

AUEL, Matias Caldas; DE MENDONÇA, Helder Ferreira. Macroeconomics relevance of credit channels: evidence from on emerging economy under inflation targeting. EconomicModelling, n⿳28, p 965979. [S.I.]. 2011. Disponivel em:http://ac.elscdn.com.ez24.periodicos.capes.gov.br/S0264999310002373/1-s2.0-S0264999310002373main.pdf?_tid=fc30a942-6f19-11e4-bf6a00000aab0f26\&acdnat=1416311992_dc8579b1e7af8c3b8d871837648b4a01Acesso em 06/11/2014.

Página 93 Caderno de Ciências Sociais Aplicadas, Vitória da Conquista/BA, vol. 14, n 24, ano 14, p. 77-96, jul/dez 2017. 
CAGNIN, Rafael Fagundes et al. A gestão macroeconômica do governo Dilma (2011 e 2012). Novos estud. - CEBRAP, São Paulo, n. 97, nov. $2013 . \quad$ Disponível em http://www.scielo.br/scielo.php?script=sci_arttext\&pid=S0101$33002013000300011 \& \operatorname{lng}=$ en\&nrm $=$ iso Acessado em 30/10/2014

CAVALCANTI, Marco A.F.H.; VONBUN, Christian. Evolução da Política do Recolhimento Compulsório no Brasil Pós-Real. Texto para discussão, no 1826. IPEA. Brasília, abril de 2013. Disponível em: http://repositorio.ipea.gov.br/bitstream/11058/1229/1/TD_1826.pdf Acessado em 27/07/2015

BRESSER-PEREIRA, Luiz Carlos; SILVA, Cleomar Gomes. O regime de metas de inflação no Brasil e a armadilha da taxa de juros/câmbio. In: OREIRO, José Luís (org.); DE PAULA, Luiz Fernando (org.); SOBREIRA, Rogério. Politica monetária, bancos centrais e metas de inflação: teoria e experiência brasileira. Editora FGV, p.21-51. 2009.

CARVALHO, Fernando J. Cardim de et al. Economia monetária e financeira: teoria e politica. Editora Campus, $9^{a}$ reimpressão. Rio de Janeiro. 2007.

CARVALHO, Fernando J. Cardim de. Uma contribuição ao debate em torno da eficácia da política monetária e algumas implicações para o caso do Brasil. Rev. Economia Política, São Paulo, v. 25, n. 4,2005. Disponível em http://www.scielo.br/scielo.php?script=sci_arttext\&pid=S0101$31572005000400001 \& \operatorname{lng}=$ pt\&nrm=iso Acesso em 08/10/2014.

DA SILVA, Guilherme Jonas Costa; OREIRO, José Luís da Costa; DE PAULA, Luiz Fernando. Spread Bancário no Brasil: uma avaliação empírica recente. In: OREIRO, José Luís da Costa (org.); DE PAULA, Luiz Fernando (org.). Sistema Financeiro: uma análise do setor bancário brasileiro. Rio de Janeiro, Editora Campus, p.191-220. 2007.

DE MENDONÇA, Helder Ferreira; SOUZA, Gustavo José de Guimarães e. Is inflation targeting a good remedy to control inflation? Journal of Development Economics 98 178-191. 2012. Disponível em http:/ / ac.els-cdn.com.ez24.periodicos.capes.gov.br/S030438781100068X/1-s2.0-S030438781100068Xmain.pdf?_tid=0e3621ca-6f1b-11e4-9d51-

00000aab0f02\&acdnat=1416312452_04c6c988e828f57cb0d400862b0d95a0Acesso em: 06/11/2014.

DE MENDONÇA, Helder Ferreira; DEZORDI, Lucas Lautert; CURADO, Marcelo Luiz. A determinação da taxa de juros em uma economia sob metas de inflação: o caso brasileiro. In: OREIRO, José Luís (org.); DE PAULA, Luiz Fernando (org.); SOBREIRA, Rogério. Política monetária, bancos centrais e metas de inflação: teoria e experiência brasileira. Editora FGV, p.165-185. 2009.

DE MENDONÇA, Helder Ferreira. Mecanismos de transmissão monetária e a determinação da taxa de juros:uma aplicação da regra de Taylor ao caso brasileiro. Economia e Sociedade, Campinas, no 16, 2001. Disponível em http://www.ie.ufrj.br/moeda/pdfs/mecanismos_de_transmissao_monetaria.pdf Acesso em 06/11/2014.

FONSECA, Marcos Wagner da. Política monetária e o canal de crédito no Brasil: uma revisão da literatura. In: OREIRO, José Luís (org.); DE PAULA, Luiz Fernando (org.); SOBREIRA, Rogério. Política monetária, bancos centrais e metas de inflação: teoria e experiência brasileira. Editora FGV, p.237-287. 2009.

Página 94 Caderno de Ciências Sociais Aplicadas, Vitória da Conquista/BA, vol. 14, n 24, ano 14, p. 77-96, jul/dez 2017. 
FONSECA, Marcos Wagner da.Mecanismos de transmissão da politica monetária no Brasil: uma análise pósregime de metas de inflação. Curitiba, 2008. Disponível em http:/ livros01.livrosgratis.com.br/cp096210.pdf Acesso em 06/11/2014.

GUJARATI, Damodar N.; PORTER, Dawn C. Econometria Básica. Editora AMGH, $5^{\text {a }}$ edição. Porto Alegre. 2011.

LOPREATO, Francisco Luiz C. O papel da política Fiscal: um exame da visão convencional. Texto para discussão, $\quad \mathrm{n}^{\circ} \quad$ 119. IE/UNICAMP. Campinas, fev. 2006. Disponível em:http://www.iececon.net/arquivos/publicacoes_39_313587953.pdf Acesso em 27/10/2014

MANHIÇA, Félix Antônio; JORGE, Caroline Teixeira. O nível da taxa básica de juros e o Spread bancário no Brasil: Uma análise de dados em painel. Texto para discussão, $\mathrm{n}^{\circ}$ 1710. IPEA. Rio de Janeiro, fevereiro de 2012. Disponível

http:/ / repositorio.ipea.gov.br/bitstream/11058/1252/1/TD_1710.pdf Acesso em 21/09/2015

MOLLO, Maria de Lourdes Rollemberg. Ortodoxia e heterodoxia monetárias:a questão da neutralidade da moeda. Revista de Economia Política, São Paulo, v. 24, n 3, 2004. Disponível em http://www.rep.org.br/PDF/95-1.PDF Acesso em 27/10/2014

MONTES, Gabriel Caldas; FEIJÓ, Carmem Aparecida.Metas da inflação e política monetária: uma abordagem considerando o processo de formação de preços em economias monetárias. In: OREIRO, José Luís (org.); DE PAULA, Luiz Fernando (org.); SOBREIRA, Rogério. Política monetária, bancos centrais e metas de inflação: teoria e experiência brasileira. Editora FGV, p. 714-96. 2009.

OLIVEIRA, Raquel de Freitas et al. Atuação de Bancos Estrangeiros no Brasil: mercado de crédito e de derivativos de 2005 a 2011. Banco Central do Brasil, trabalhos para discussão, 298. 2012. Disponível em: http://www.bcb.gov.br/pec/wps/port/wps298.pdf Acesso em 05/03/2015.

ONO, Fábio Hideki et al. Spread bancário no Brasil: determinantes e proposições de política. Desenv15, p. 345-379. 2004. Disponível em:http://www.luizfernandodepaula.com.br/ups/spread-bancario-nobrasil-determinantes-e-proposicoes-para-politica.pdfAcesso em 27/10/2014

OREIRO, José Luís da Costa et al. Determinantes macroeconômicos do spread bancário no Brasil:teoria e evidência recente. Economia Aplicada. Ribeirão Preto, v. 10, n. 4, p. 609-634. 2006. Disponível em http://www.scielo.br/scielo.php?script=sci_arttext\&pid=S141380502006000400007\&lng=en\&nrm=iso Acesso em 06/11/2014.

PRATES, Daniela Magalhães; CUNHA, André Moreira. Estratégias macroeconômicas depois da crise financeira global:o Brasil e os emergentes. Indic. Econ. Porto Alegre, V.39, n.1, p. 67-82, 2011. Disponível em:http://revistas.fee.tche.br/index.php/indicadores/article/view/2582/2956Acesso em: $27 / 10 / 2014$

RIBEIRO, João Daniel Tisi. A crise financeira internacional e seus reflexos na política macroeconômica do Brasil (2007-2009). 2010. 76p. Trabalho de conclusão de curso (Especialização em Relações

Página 95 Caderno de Ciências Sociais Aplicadas, Vitória da Conquista/BA, vol. 14, n 24, ano 14, p. 77-96, jul/dez 2017. 


\section{- CADERNOS de CIENCIAS SOCIAIS APLICADAS}

Internacionais) - Curso de pós-graduação em Relações Internacionais, Universidade de Brasília, Brasília, 2010. Disponível em:http://bdm.unb.br/handle/10483/1050 Acesso em 06/11/2014.

SOUZA SOBRINHO, Nelson Ferreira. Uma avaliação do canal de crédito no Brasil. Banco Nacional de Desenvolvimento Econômico e Social, 2003. Disponível em http://www.bndes.gov.br/SiteBNDES/export/sites/default/bndes_pt/Galerias/Arquivos/conhecime nto/premio/pr252.pdf Acesso em 27/10/2014.

TAVARES, Debora Pereira; MONTES, Gabriel Caldas; GUILLÉN, Osmani Teixeira de Carvalho. Transmissão da política monetária pelos canais de tomada de risco e de crédito: uma análise considerando os seguros contratados pelos bancos e o spread de crédito no Brasil. Trabalbo para discussão n³8. Banco Central do Brasil. Brasília. 2013. 